\title{
Effects of $\mathrm{Sr}^{2+}$ impurity on the nucleation and growth of barite investigated by optical microscopy and $X$-ray nanotomography
}

KE YUAN ${ }^{1}$, VITALIY STARCHENKO ${ }^{1}$, NIKHIL RAMPAL ${ }^{2}$, FENGCHANG YANG ${ }^{1}$, XIANGHUI XIAO ${ }^{3}$ AND ANDREW G STACK $^{1}$

${ }^{1}$ Oak Ridge National Laboratory

${ }^{2}$ Columbia University

${ }^{3}$ Brookhaven National Laboratory

Presenting Author: yuank@ornl.gov

Understanding the role of impurities in mineral nucleation and growth is crucial for various applications in environmental and geochemical sciences. Here, we used barite $\left(\mathrm{BaSO}_{4}\right)$ as a model system to show the impact of $\mathrm{Sr}^{2+}$ on its heterogeneous nucleation and growth kinetics using a classical optical microscopy approach combined with the advanced X-ray nanotomography [1]. In situ X-ray nanotomography data revealed the $3 \mathrm{D}$ distributions of barite crystals nucleating in solutions, where the addition of $\mathrm{Sr}^{2+}$ ions increased the nuclei density while inhibiting the barite growth. Optical microscopy data significantly underestimated the nuclei density due to its finite resolution, but results obtained from both methods showed that barite nucleation followed the classical nucleation theory. Fitted data obtained from X-ray nanotomography showed a larger pre-factor term with both methods yielded a similar interfacial energy term. The comparison between results obtained from two methods showed the importance of instrumental resolution on determination of kinetic factors.

[1] K Yuan, V Starchenko, N Rampal, F Yang, X Xiao, WK Lee, AG Stack. Counter effects of impurity ion $\mathrm{Sr}^{2+}$ on the heterogeneous nucleation and growth of barite $\left(\mathrm{BaSO}_{4}\right)$, in prepare. 